\title{
EVSItalia Database HABITAT OF ITALY
}

\author{
Michele De Sanctis, Diego D'Angeli, Anna Testi \& Fabio Attorre
}

\begin{abstract}
The EVSItalia Database HABITAT OF ITALY (GIVD ID EU-DIT-018) contains 5,441 relevés (including 2,422 taxon names). $58 \%$ of the relevés come from the scientific literature; the remaining $42 \%$ have been collected by the authors during several field campaigns carried out between 2001 and 2011. Phytosociological investigation followed the methods described by Westhoff and van der Maarel and Braun-Blanquet. The location of the relevés was selected in relation to the homogeneity of the physical features, vegetation structure and species distribution. According to these criteria different kinds of habitats were sampled in the Italian territory: sand dunes, wetlands, woodlands, shrublands and grassland (from the coast to the Alpine belt) etc. The main focus of the database is to collect and store bibliographic relevés of Italian forest vegetation. The database was created using TURBOVEG.
\end{abstract}

Keywords: Italian vegetation; phytosociology; TURBOVEG.

GIVD Database ID: EU-IT-018

Last update: $2012-07-08$

\section{EVSItalia Database HABITAT OF ITALY}

Scope: The database aims to store information from published/certified phytosociological sources and our original relevés of Italian vegetation. Status: completed and continuing Period: 1958-2011

Database manager(s): Michele De Sanctis (michedes@gmail.com); Diego D'Angeli (d.dangeli@tiscali.it); Fabio Attorre (fabio.attorre@uniroma1.it)

Owner: Michele De Sanctis

Institution: Department of Environmental Bioogy, University Sapienza of Rome

P.le Aldo Moro 5, 00185 Rome

e-mail: michedes@gmail.com

mobile: +39 3282310341

Web address: [NA]

Availability: according to a specific agreement

Database format(s): TURBOVEG

Online upload: [NA]

Online search: [NA]

Publication: [NA]

Plot type(s): normal plots

Export format(s): TURBOVEG, MS Access, Excel

Non-overlapping plots: 5,441

Plot-size range: $0.1-200 \mathrm{~m}^{2}$

Total plot observations: 5,441

Estimate of existing plots: [NA]

Completeness: [NA]

Countries: IT: $100.0 \%$

Number of sources: 58

Valid taxa: [NA]

Forest: [NA] - Non-forest: [NA]

Guilds: all vascular plants: $100 \%$

Environmental data: altitude: $49 \%$; slope aspect: $47 \%$; slope inclination: $51 \%$

Performance measure(s): cover: 100\%

Geographic localisation: GPS coordinates (precision $25 \mathrm{~m}$ or less): $27 \%$; point coordinates less precise than GPS, up to $1 \mathrm{~km}$ : $14 \%$

Sampling periods: $[N A]$

Information as of 2012-07-12; further details and future updates available from http://www.givd.info/ID/EU-IT-018

Michele De Sanctis* (michedes@gmail.com), Diego D'Angeli (d.dangeli@tiscali.it), Anna Testi (anna.testi@uniroma1.it), Fabio Attorre (fabio.attorre@uniroma1.it)

Department of Environmental Biology, Sapienza University of Rome, P.le Aldo Moro, 5, 00185 Rome, ITALY

*Corresponding author 